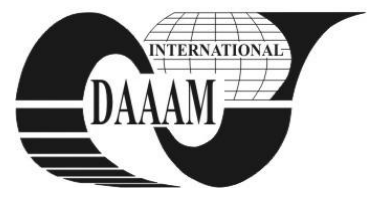

\title{
WETTING OF CTP OFFSET PLATE AS A FUNCTION OF DEVELOPING PROCESS
}

\author{
TOMASEGOVIC, T[amara]; CIGULA, T[omislav]; MAHOVIC POLJACEK, S[anja] \& GOJO, M[iroslav]
}

\begin{abstract}
Offset printing is a complex process where many parameters, such as fountain solution properties and plate making process greatly influence quality of the final product. Aim of this paper was to determine physical-chemical poperties of two fountain solution types and their wetting properties on printing plates made in different process conditions. Obtained results show that $\mathrm{pH}$ value and contact angle decreases as volume of added concentrate in fountain solution increases, while electrical conductivity enhances. Measurments of the contact angle showed that the increase of developing speed causes higher values of contact angle. This investigation showed that both of investigated parameters, fountain solution and developing process, significantly influence wetting process, consequently printing quality.
\end{abstract}

Key words: offset printing plate, fountain solution, electrical conductivity, $p H$ value, contact angle

\section{INTRODUCTION}

On the offset printing plate geometrical difference between printing and nonprinting areas is negligible, so selective adsorption of printing ink is achieved by different physicalchemical properties. The nonprinting areas are made of hydrophilic $\mathrm{Al}_{2} \mathrm{O}_{3}$ which enables them to adsorb water-based fountain solution, while printing areas are built from oleophilic and hydrophobic photoactive layer which in the printing process adsorbes oil-based printing ink. Different composition and properties of the fountain solutions may cause poor wetting resulting with low-quality imprint. Investigations in the field of fountain solution's composition and properties have been made so far (S. S. Deshpande).

The aim of this paper is to examine physical and chemical properties of two fountain solutions made with different concentrates applied on Computer to Plate (CtP) offset printing plates with variations in developing time.

\section{PLATE WETTING AND FOUNTAIN SOLUTION PROPERTIES}

Wetting is a phenomenon which occurs when solid and liquid phase come in contact. Wetting quality is observed by measuring contact angle. Contact angle is defined as the angle between the tangent on the liquid drop and the tangent on the solid surface in the point where all three phases (gas, liquid and solid) meet. The lower the contact angle, the better is the wetting.

Fountain solution is a water-based solution in which some substances (surfactantant, buffer, biocides etc.) are added to improve its properties. Main purpose of fountain solution is the oleophobization of the nonprinting areas (Kipphan H., Mahovic Poljacek $\mathrm{S}$ et al.). Applying the fountain solution onto nonprinting areas enhances their oleophobic character and rejection of the printing ink. Many various printing plates and fountain solutions are present on the market. Having in mind ecological and economical approach one should investigate fountain solution - printing plate combinations to diminish negative ecological influence, but in the same time keep the desired printing quality level.

On the other hand, processing of the printing plate has significant impact on the printing plate quality, consequently on printing process (Baracic et al., 2009). CtP improved standardization of exposure, but developing process must be examined and optimized in order to enable good fountain solution and/or printing ink adsorption (Zitinski et al., 2009).

\section{EXPERIMENTAL}

\subsection{Sample preparation and measurements}

For the investigation two fountain solutions (Solution 1 and Solution2) from different manufacturers were used. Samples of the fountain solutions were prepared by adding the concentrate in demineralized water, starting from $0 \%$ to $10 \%$ vol successively increasing the concentration for $2 \%$ vol. Thus eleven samples of each fountain solution were made.

Measurement of the $\mathrm{pH}$ value and electrical conductivity were performed to get insight of fountain solution samples' properties which are monitored also throughout printing process. In order to determine influence of the developing process on the wetting of nonprinting areas, three samples were prepared, first developed at developing speed of $720 \mathrm{~mm} / \mathrm{min}$, second at $900 \mathrm{~mm} / \mathrm{min}$ and third at $1080 \mathrm{~mm} / \mathrm{min}$. Measurements of contact angle were performed by Dataphysics OCA 30 using Sesile drop method.

\subsection{Results and discussion}

Results of investigations show that prepared fountain solutions differ by their physical-chemical properties. Solution 1 has higher values of $\mathrm{pH}$ and electrical conductivity in comparison with Solution 2 (Fig. 1). Solutions of lower concentrations have too high $\mathrm{pH}$ value, which might damage the aluminium oxide layer, and low electrical conductivity that could result with problems in fountain solution transfer. Fig.2. shows that increasing the added amount of the concentrate causes a steady decrease in contact angle's value.

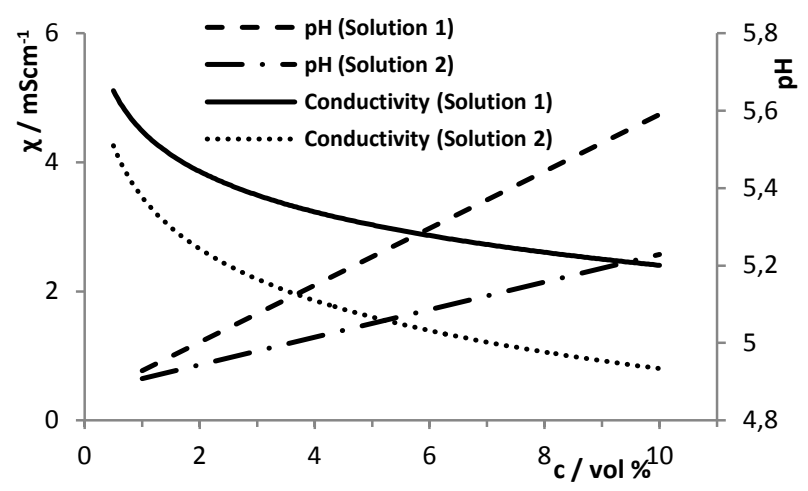

Fig. 1. Dependence of electrical conductivity and $\mathrm{pH}$ value of the fountain solution on its concentration 


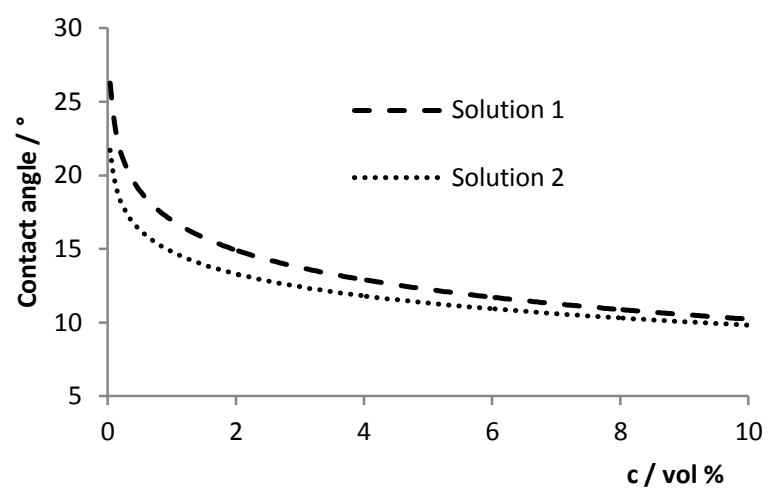

Fig.2. Dependence of contact angle of fountain solution on its concentration for Sample 1 and Sample 2, $\mathrm{v}_{\mathrm{d}}=720 \mathrm{~mm} / \mathrm{min}$

With lower concentrations, the decrease is significant, while by increasing the fountain solution's concentration contact angle's value streams to a constant value. Sample 2 shows slightly lower values of contact angle compared to Sample 1, which indicates better wetting.

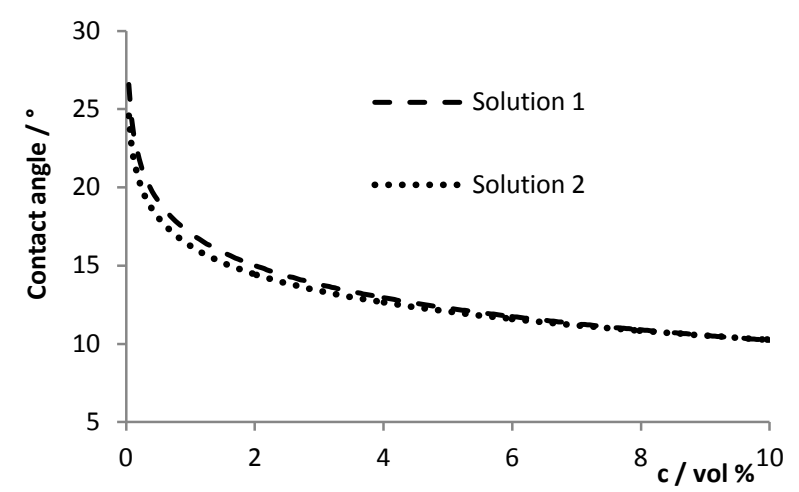

Fig.3. Dependence of contact angle of fountain solution on its concentration for Sample 1 and Sample 2, $\mathrm{v}_{\mathrm{d}}=900 \mathrm{~mm} / \mathrm{min}$

At a developing speed of $900 \mathrm{~mm} / \mathrm{min}$ (Fig. 3) the behavour of contact angle values is similar to the developing speed of $720 \mathrm{~mm} / \mathrm{min}$. At lower amount of added concentrate Sample 2 also shows slightly lower values of the contact angle, while at higher amount of added concentrate (over $6 \%$ vol) both samples have approximately the same value of the contact angle. Increasing the developing speed to $1080 \mathrm{~mm} / \mathrm{min}$ (Fig. 4) the dependence of contact angle on the concentration of fountain solution is generally higher than with the developing speed of 720 and $900 \mathrm{~mm} \mathrm{/} \mathrm{min.} \mathrm{Sample} 1$ shows a considerably higher values of the contact angle compared to Sample 2 and thus lower level of adsorption of the fountain solution onto nonprinting areas.

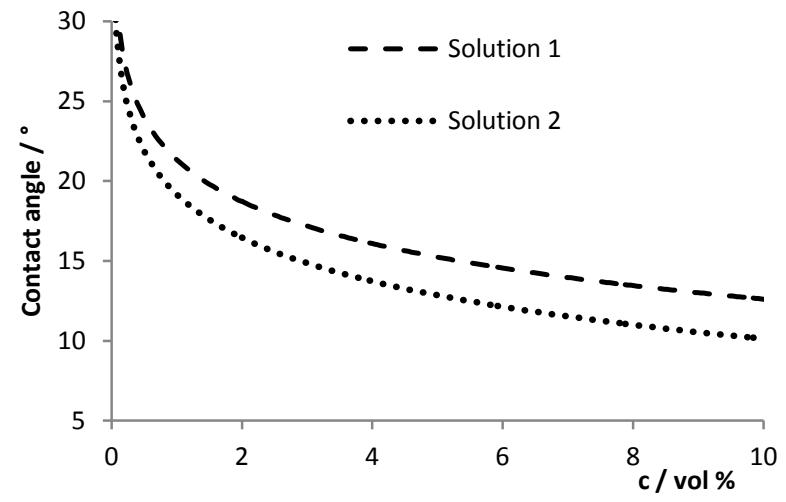

Fig. 4. Dependence of contact angle of fountain solution on its concentration for Sample 1 and Sample 2, $\mathrm{v}_{\mathrm{d}}=1080 \mathrm{~mm} / \mathrm{min}$

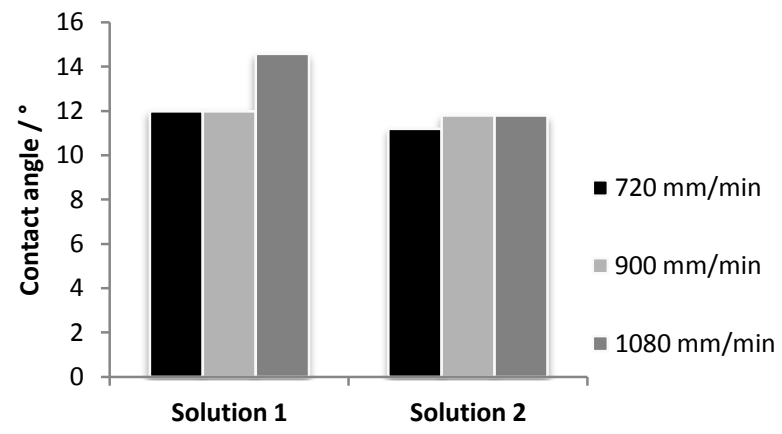

Fig. 5. Contact angles of fountain solutions' samples at $6 \%$ vol at different developing speeds

In figure 5 one can see contact angle values of fountain solution samples at $6 \%$ vol at investigated developing speeds. It can be seen that best wetting results are obtained with Solution 2 on printing plate developed at developing speed of 720 $\mathrm{mm} / \mathrm{min}$. On the other hand, worst results are noticed by Solution 1 on printing plate developed in the shortest time (developing speed $1080 \mathrm{~mm} / \mathrm{min}$ ).

\section{CONCLUSION}

Obtained results showed that used concentrate for fountain solution has a significant impact on its electrical conductivity and $\mathrm{pH}$ value. Concentrate used for composure of Solution 2 has smaller influence on $\mathrm{pH}$ value and electrical conductivity than concentrate for Solution 1. $\mathrm{pH}$ value of both solutions increases linearly with increasing value percentage of concentrate. From contact angle measurements one can conclude that adding concentrate causes decrease of contact angle value. Printing plate made with developing speed of 720 $\mathrm{mm} / \mathrm{min}$ shows nealy the same wetting with both solutions. Results indicate that in investigated conditions would be best to use developing speed of $720 \mathrm{~mm} / \mathrm{min}$ and Solution 2. In addition, this research proved significance of observed parameters and implies necessity of conducting investigation when changing working materials in order to sustain needed quality level of production. For the complete understranding and optimization of the plate making process one should conduct thorough research which will be directed in determination of all other process parameters significance.

\section{REFERENCES}

Baracic M., Cigula T., Tomasegovic T., Zitinski Elias P. Y., Gojo M. (2009). Influence of Plate Making Process and Developing Solutions on the Nonprinting Areas of Offset Printing Plates, Proceedings, $20^{\text {th }}$ International DAAAM Symposium: "Intelligent Manufacturing \& Automation: Theory, Practice \& Education", (ed. B. Katalinic), ISBN 978-3-901509-70-4, Vienna, Austria

Deshpande S. S. (2011.). Fountain solution in lithographic offset printing, Journal of Engineering Research and Studies, E-ISSN0976-7916, Beed

Kipphan H. (2001.). Handbook of print media, Springer-Verlag, ISBN 978-3-540-67326-2, Heidelberg, Germany

Mahovic Poljacek S.; Agic D. \& Gojo M. (2006.). Influence of the Chemical Processing on the CtP Printing Forms, Annals of DAAAM for 2006. and Proceedings of 17th International DAAAM Symposium (ed. B. Katalinic), ISBN 3-901509-57-7, Vienna, Austria

Zitinski Elias P. Y., Tomasegovic T., Cigula T. (2009.). Differences in Physical-Chemical Properties of the Nonprinting Areas for Conventional and CtP Process, Printing Future Days 09 Proceedings, ISBN: 978-3-89700108-4, Chemnitz, Germany 